\title{
Calibration of a numerical model for bore-and-fill mining
}

\author{
by D. Roberts
}

\section{Synopsis}

Bore-and-fill mining was implemented at a pilot site in Tau Tona mine's shaft pillar on 97 level. Observations, scan data, and measurements from this site were used to calibrate an inelastic numerical model of bore-andfill mining within the Carbon Leader Reef (CLR).

Borehole breakout was found to occur around holes at the site as they were bored. A strike-parallel exposure showed that fracturing within the Carbon Leader stratum extended far beyond the breakout (up to $1.2 \mathrm{~m}$ from the hole sidewall). This was confirmed by borehole camera observations in a hole drilled on-reef through a bored-and-filled hole.

A Mohr-Coulomb strain-softening model was calibrated against the observed fracturing. It was found that it was necessary to include interfaces corresponding with CLR contacts to replicate the extent of fracturing that was observed. The effect of hole position on breakout was quantified by analysing hole scan data. Models with holes at various positions, together with this data, were used to calibrate the upper and lower CLR contact properties. A novel displacement-based method for simulating breakout was developed for use on Carbon Leader models. Although the breakout distributions were not precisely matched, the modelled values lay within the extremes that were observed. Trends and other features observed underground were also replicated.

Modelled stresses and measured stress histories showed similar responses to the boring of nearby holes, but the magnitudes differed by varying degrees in each stress component. The modelled subvertical stress changes were generally lower than those measured, though both were greater than those obtained from a virgin stress measurement in the fill. It was noted that either measured value could be obtained by simply shifting the measurement position in the model. The strike stresses correlated reasonably well. Dip stresses were very different: measured tensile stresses greater than the fill strength suggest that these measurements were erroneous.

The result of this work is a calibrated plane strain model that can be used to study the effects of geology, mining sequence, and fill properties on the rock mass response to bore-and-fill mining.

\section{Keywords}

bore-and-fill mining, borehole breakout, strain-softening model, stress changes. are associated with increased seismic hazard.

Optimization of the boring sequence and in-hole support enable the extraction of as much of the reef as possible, while minimizing waste rock mining. Support must be installed in such a way that workers are never required to enter the holes. Filling the holes with a stiff, strong material will achieve these goals.

Concrete, for example, has low porosity, can be engineered to have high strength and stiffness, and is easily poured or pumped into the holes from service excavations.

This paper describes how observations and measurements at a reef-boring pilot site were used to calibrate nonlinear numerical models. Initial models were calibrated based on observations of breakout and additional fracturing that was exposed when a raise was mined along the axis of an existing hole. A novel criterion for simulating breakout was developed, based on displacement into the hole and parallel to the minor stress axis. This criterion was used with the calibrated model to simulate the drilling and filling of a sequence of five holes. Some of these holes were instrumented with stress-change gauges and some were scanned and surveyed. The in situ data was compared with modelled outcomes.

\section{Reef boring background}

The feasibility of reef boring was considered by Jager, Westcott, and Cook (1975). They analysed various reefs in terms of deviation from planarity, presenting charts and tables to indicate optimal hole diameters in different mining areas. Adams (1978) describes stoping using a raiseboring machine on the Carbon Leader Reef (CLR) at West Driefontein mine. Holes were drilled adjacent to each other to create a continuous slot between reef drives. Pilot holes were bored and then used to guide a raisebore reamer from the upper reef drive. The completed slot is shown in Figure 1.

* CSIR, Johannesburg, South Africa.

(C) The Southern African Institute of Mining and Metallurgy, 2017. ISSN 2225-6253. Paper received Apr. 2016; revised paper received Jan. 2017. 


\section{Calibration of a numerical model for bore-and-fill mining}

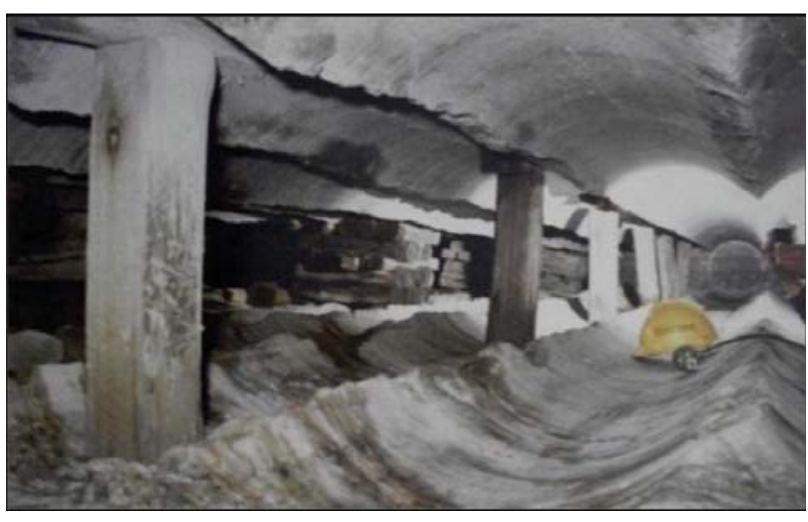

Figure 1-The completed slot bored by sequential raisebore holes at West Driefontein (Adams, 1978)

It was observed that the first and last $0.5 \mathrm{~m}$ of each hole showed very little damage. Spalling did not occur when holes were bored into fractured (de-stressed) ground, while extensive spalling occurred when holes were bored into highly stressed, unfractured ground adjacent to the fractured material. Breakout occurred while the holes were being bored. Without filling, falls of ground (FOGs) occurred in the slot and time-dependent damage was observed after completing the slot.

It was concluded that fracturing was inevitable and that no fill could prevent breakout. Simple calculations showed that over 164 holes needed to be drilled before the fill would start to take the full overburden load. Jager, Westcott, and Cook (1975) commented that it would be necessary to fill the holes with 'a relatively incompressible material' not more than $2 \mathrm{~m}$ away from the hole being bored.

In the current work, it is acknowledged that the fill cannot prevent fracturing, but it is emphasized that this is not the intended purpose of the fill. The effectiveness of the fill is not in sustaining the 'full overburden load', but in reducing closure and limiting the stress transferred to the abutments of the extracted reef zone. By doing this, the occurrence of large-scale fractures at the edge of the extracted zone will be prevented, and bed separation will be limited to the extent that fallout does not occur in nearby service excavations.

\section{Underground observations}

\section{Pilot site description}

The pilot site for the boring and filling operations is on Tau Tona mine within the shaft pillar on 97 level. The location of the site is shown in Figure 2. The site is a $30 \times 50 \mathrm{~m}$ pillar created between two reef drives on strike and raises on dip. The reef drives and raises are nominally $3.5 \mathrm{~m} \times 3.5 \mathrm{~m}$, though the lower reef drive was up to $5 \mathrm{~m}$ wide, as the northern sidewalls were sliped and the southern sidewalls cut away to accommodate the boring machine.

The CLR is exposed in all these service excavations. The average channel width exposed in the western raise is 24.9 $\mathrm{cm}$, although scans from holes bored within the pillar indicated thicknesses greater than $40 \mathrm{~cm}$. The reef dips at $23^{\circ}$. The footwall is a medium- to coarse-grained, slightly argillaceous quartzite containing footwall pebble bands. The hangingwall is a medium-grained, slightly argillaceous quartzite with occasional milky white quartz veins. Quartz veins tend to be oriented NE-SW and either terminate on the reef's bottom contact or cut through the reef. No major geological structures were observed. The Green Bar argillite (Ryder and Jager, 2002) lies approximately $2.0 \mathrm{~m}$ above the top reef contact. The basal Green Bar contact is not exposed, so ground control problems associated with it were not expected at the pilot site.

Map3D boundary element modelling was employed to estimate the stress state. The stress gradient was specified to correspond with previous virgin stress measurements at Tau Tona (Hofmann, Scheepers, and Ogasawara, 2013). A model of the shaft pillar area was analysed with interrogation grids around the 97 level pillar. The following stress state was obtained:

Reef-perpendicular stress: $\quad 107.5 \mathrm{MPa}$

Strike-parallel stress: $\quad 0.44 \times \sigma_{\mathrm{yy}}=47.3 \mathrm{MPa}$

Dip-parallel stress: $\quad 0.74 \times \sigma_{\mathrm{yy}}=79.6 \mathrm{MPa}$

Since the holes are drilled on-reef, the stress field is oriented so that the major principal stress is perpendicular to the hole axis and perpendicular to the Carbon Leader contacts. For a section perpendicular to the hole axis, the effective stress field is shown in Figure 3.

\section{Breakout observations}

Initial holes were drilled at least five diameters apart, resulting in no stress interaction between the holes. The resulting breakout damage was consistent with observations at West Driefontein, that is:

> The first and last 1.0-1.5 $\mathrm{m}$ of the hole were undamaged

> Breakout was oriented along the minor principal stress axis (i.e. in the horizontally opposed sidewalls)

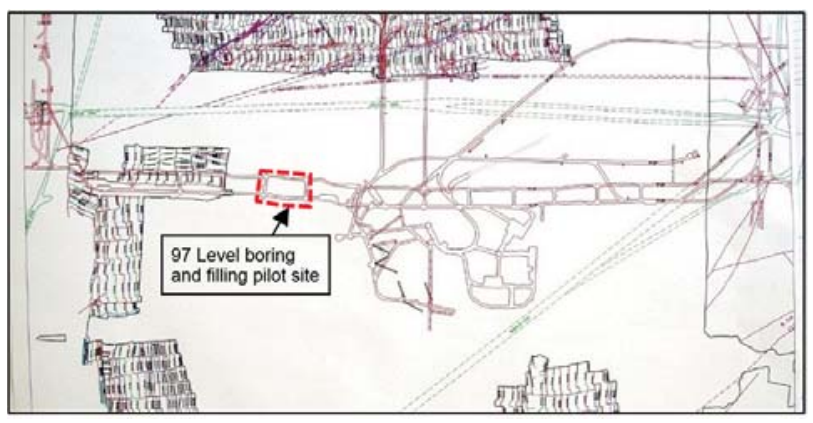

Figure 2-Tau Tona shaft pillar area, indicating the location of the pilot site

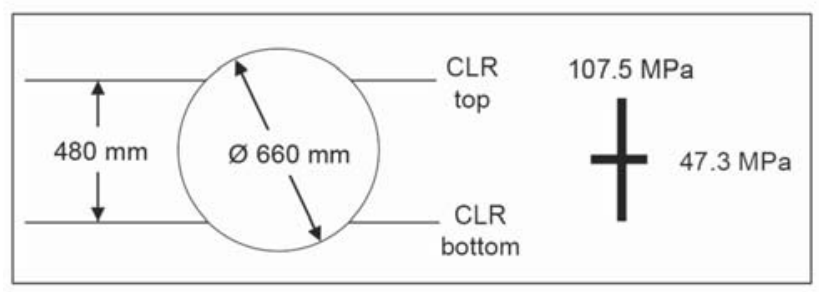

Figure 3-Geometry of a typical bored hole relative to the CLR contacts and the orientation of the stress field in the plane perpendicular to the hole axis 


\section{Calibration of a numerical model for bore-and-fill mining}

> Breakout occurred during drilling, with almost no timedependent failure being observed.

It was also noted that the fractures tended to break out against the upper CLR contact. This was particularly evident in hole 12 (Figure 4). The extent of breakout was found to vary considerably between holes, and even along the length of some holes. Many of the holes were scanned to quantify the extent, shape, and volume of the breakout. In the following discussions the breakout volume for a given section is expressed in $\mathrm{m}^{3} / \mathrm{m}$, that is, volume broken out per metre of hole length. This is equivalent to the broken out area (in $\mathrm{m}^{2}$ ) for that section.

Figure 5 shows the condition of hole 10 as is viewed from the southern reef drive. The hole profiles generated for the southernmost $6 \mathrm{~m}$ of the hole are also shown.

Figure 6 shows a photograph of the same hole taken from the northern reef drive, along with the topmost hole profiles. It was found that this hole was drilled, initially, where the CLR package was relatively thick, resulting in significant breakout extending all the way to the CLR contacts (up to $0.18 \mathrm{~m}^{3} / \mathrm{m}$ ). The hole then deflected upwards, so much so that the upper part of the hole was drilled entirely into hangingwall quartzite. In this region the breakout was less than was typically observed in holes drilled entirely in CLR (0.025 to $\left.0.045 \mathrm{~m}^{3} / \mathrm{m}\right)$.

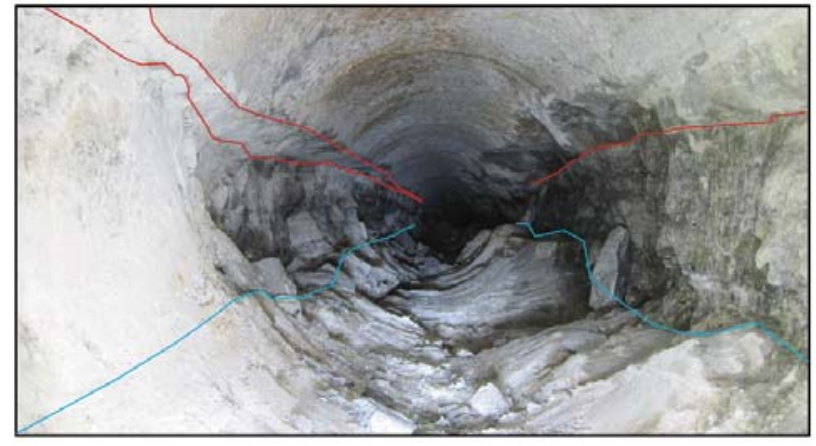

Figure 4-Photograph of hole 12 from the southern reef drive. Intersections and exposures of the CLR top and bottom contact are shown in red and blue, respectively

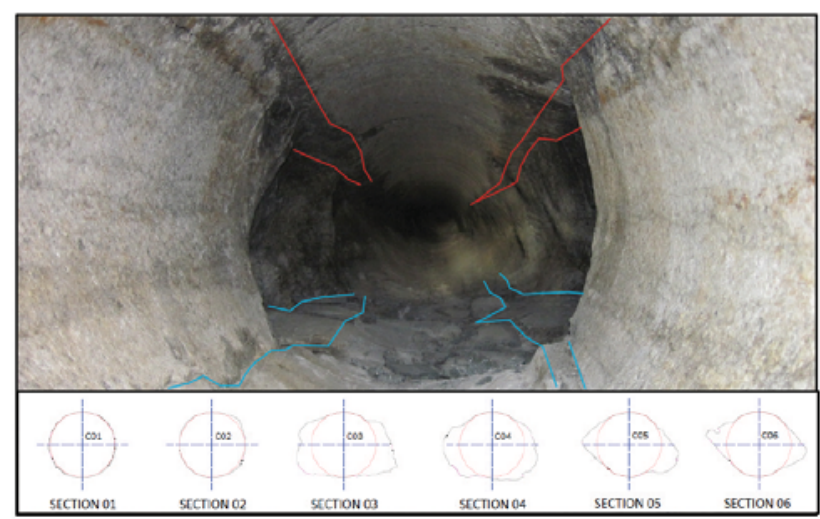

Figure 5-Photograph of hole 10 from the southern reef drive and scan profiles for the lower $6 \mathrm{~m}$ of the hole. Intersections and exposures of the CLR top and bottom contact are shown in red and blue, respectively
The breakout volumes, cumulated from the start of each hole, for a selection of the scanned $660 \mathrm{~mm}$ diameter holes are presented in Figure 7 . Holes 17 and 18 show very different levels of breakout to all the other holes. Hole 17 was drilled between holes 14 and 11, which were so closely spaced that the concrete in these holes was exposed in the sides of hole 17. At this point not enough stress had been regenerated in the fill for breakout to occur. Only towards the top of the hole, where the hourglass pillar was larger and the rock mass was exposed, was there breakout around hole 17. Hole 18 was drilled adjacent to hole 10 , effectively in the abutment created by the 11-17-14-10 sequence. This region was highly stressed, as reflected by the high volume that was broken out. The geometry of the holes in this sequence is shown in Figure 8.

The lateral (horizontal) extent of the breakout was also measured in each of the scanned holes. The maximum breakout length was measured on both sides of the hole. This data was revealing, particularly for holes that were drilled close to previously drilled and filled holes.

Figure 9 shows the distribution of the breakout extent on either side of hole 18, which was drilled adjacent to hole 11 . Initially the damage was concentrated on the western side of the hole, with almost no damage occurring in the small pillar separating holes 18 and 11. This is consistent with the observation of Adams (1978), indicating that the pillar had

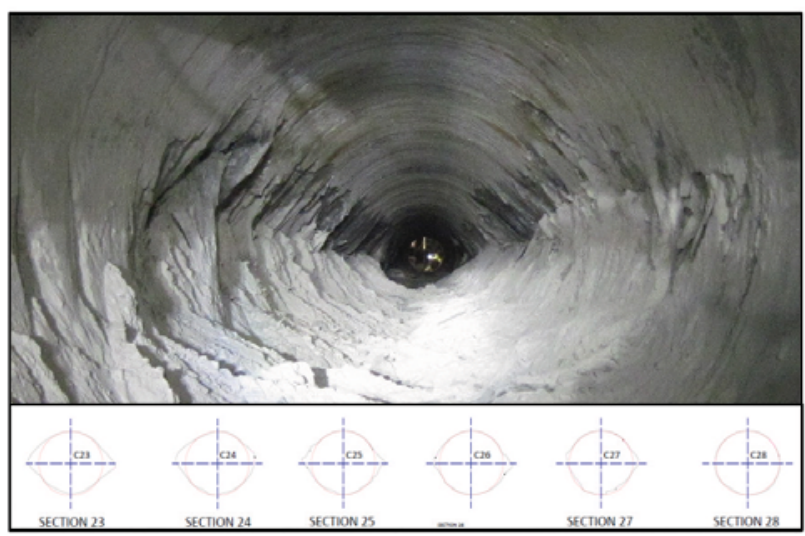

Figure 6-Photograph of hole 10 from the northern reef drive and scan profiles for the upper $6 \mathrm{~m}$ of the hole

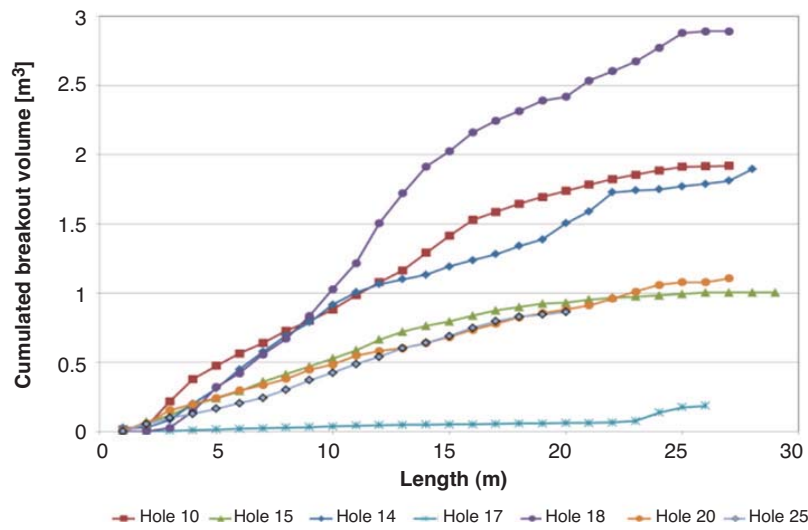

Figure 7-Breakout volume cumulated from the start of each hole 


\section{Calibration of a numerical model for bore-and-fill mining}

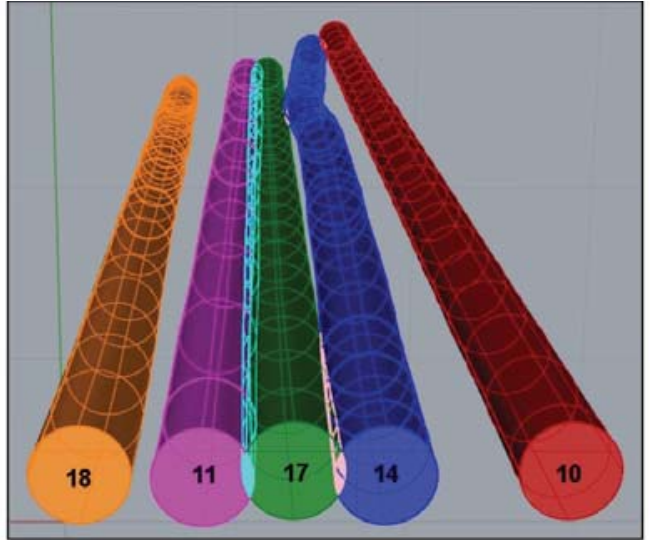

Figure 8-Geometry of the region encompassing holes $10,11,14,17$, and 18 , viewed from the southern reef drive

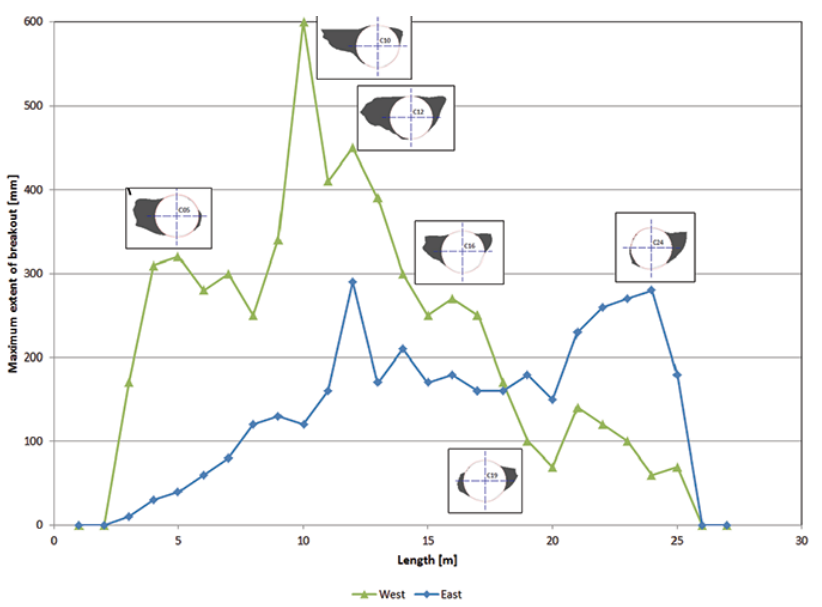

Figure 9-Maximum extent of lateral breakout on the east and west sides of hole 18 for each metre of hole length. Insets - breakout shape as seen from the southern reef drive

failed and was de-stressed, and that the adjacent rock mass was highly stressed. As Figure 8 shows, the distance between the two holes (and therefore the pillar width) gradually increased. In response to this, damage on the western side decreased, while damage in the pillar increased. At a distance of $18 \mathrm{~m}$ from the southern hole collar the breakout was symmetrical, indicating that the stress was evenly distributed between the pillar and the abutment. From this point onwards the pillar was wide enough to sustain significant stress and the extent of breakout was greater here than in the abutment.

The effect of the hole position relative to the reef was examined. Holes 10 and 18, both of which deviated significantly from the reef position, were evaluated in more detail. The extent of breakout for these holes is plotted against the approximate vertical position of the hole (relative to the centreline of the reef package) in Figure 10. Since these holes were drilled in different stress regimes, the breakout volume is normalized to the average breakout along the length of each hole. The general trend is a decrease in failure volume as the hole position moves away from the reef; however, there is also an increase when the bottom of the hole approaches the upper reef contact (from 550 to 620 $\mathrm{mm}$ ). It also appears that the breakout is greater when the top of the hole coincides with the upper contact (around $-90 \mathrm{~mm}$ ). The breakout is lower than average when the hole centreline coincides with the upper and lower reef contacts $(-240$ and $240 \mathrm{~mm})$, and when the hole is located entirely outside of the reef package $(y>560 \mathrm{~mm})$.

This data indicates that damage is increased when the top or bottom of the hole coincides with the reef contacts, in particular the upper reef plane. The breakout shape (Figure 11) show that damage extends from the sidewalls of the hole all the way up to the reef contact.

Subsequent investigation revealed that the extent of fracturing greatly exceeded that indicated by breakout alone. A hole was bored in the planned position of a reef raise in an attempt to de-stress this region. Given the high stresses in the area the risk of strain-bursting, particularly in tunnel sidewalls, was considered a potential hazard. When the reef raise was created using conventional drill-and-blast methods the full extent of fracturing around the hole was revealed (Figure 12). 'Onion-skin' fracturing was observed within the reef package up to one hole diameter $(660 \mathrm{~mm})$ distant from the sidewall of the hole. The extent of breakout (material detaching from the rock mass and falling into the hole) was limited compared to the extent of fracturing.

It was suggested that the extra fracturing around the hole could have been caused by stress induced by the advancing face of the raise. To confirm that these fractures were present prior to mining of the raise, an exploration hole was drilled on-reef through a bored-and-filled hole. The discontinuity distribution inferred from borehole camera videos is shown in Figure 13. Fractures in the sidewall of the raise dominate

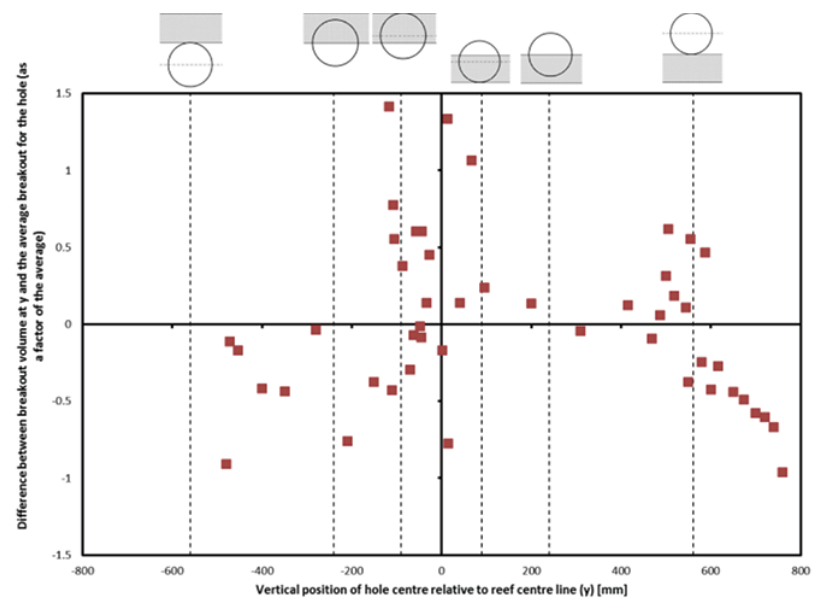

Figure 10-The effect of vertical position of the hole relative to the reef centreline for holes 10 and 18, expressed as a factor of the average breakout along each hole

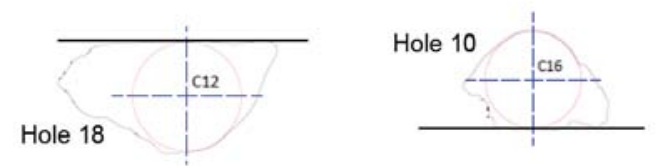

Figure 11-Breakout shapes for holes 18 and 10 where the top and bottom of the hole coincides with the upper reef contact 


\section{Calibration of a numerical model for bore-and-fill mining}

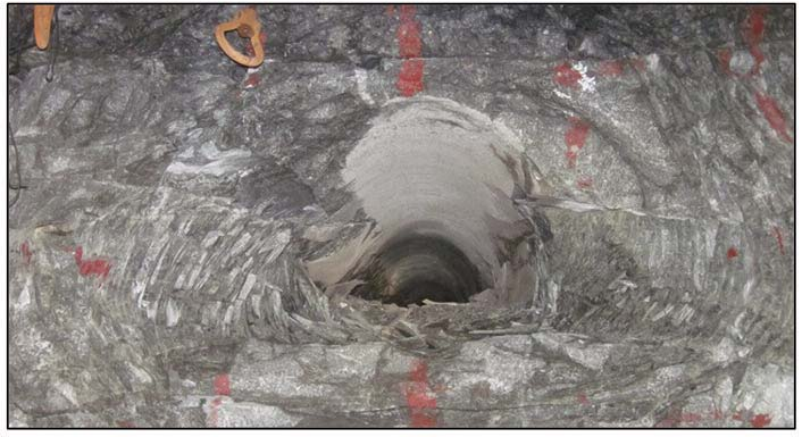

Figure 12-Photograph of exposed reef raise face, revealing extensive fracturing beyond the extent of breakout around the hole

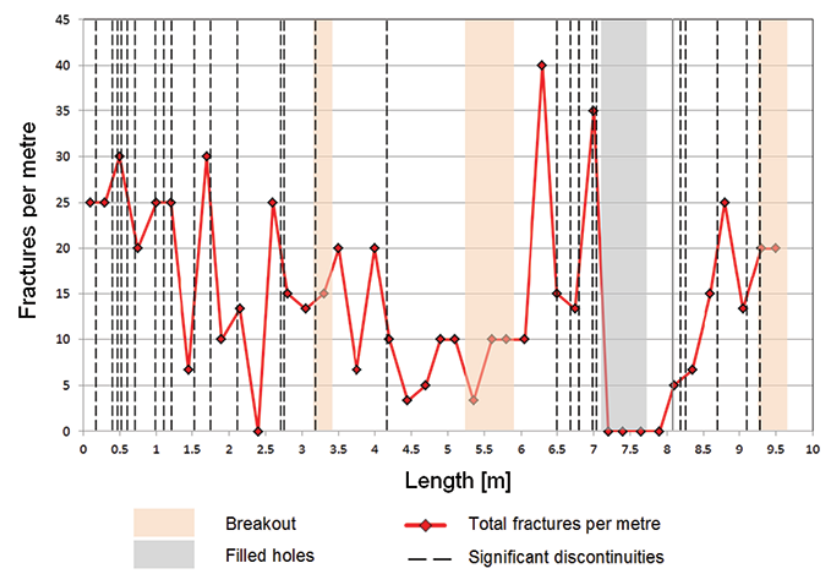

Figure 13-Discontinuity distribution inferred from borehole camera videos of an on-reef exploration hole. The length axis begins at the raise from which the hole was drilled

up to $3.2 \mathrm{~m}$. A high-stress region (breakout with few discontinuities) is evident from 3.2 to $6 \mathrm{~m}$. The region ( 6 to $7.2 \mathrm{~m}$ ) adjacent to the hole $(7.2$ to $7.7 \mathrm{~m}$ ) is highly fractured, as is the region from 8.6 to $9.3 \mathrm{~m}$, which is adjacent to another hole. This confirms that the fracture zone extends up to $1.2 \mathrm{~m}$ away from the edges of bored holes.

\section{Sequence and observations for holes 10 to 18}

A sequence of holes that were drilled close to each other was modelled.

Figure 14 shows the geometry of the holes as viewed from the lower reef drive towards the west side of the test site. The five $660 \mathrm{~mm}$ diameter holes 10 to 18 were modelled. The larger diameter holes 5 and 1 are far enough from this sequence to be ignored in the modelling. The 'VWSG' labels indicate that vibrating wire stress gauges were installed in holes 10 and 14.

In addition to the stress measurements, holes 10, 14, 17, and 18 were scanned along their entire lengths, allowing quantification of the damage in each hole, and providing accurate geometries of these holes. Hole 17 was filled for only half its length, allowing observation of the hole condition after the drilling of hole 18 from the top drive. After hole 18 was drilled, some spalling was observed in the western sidewall of hole 17 (Figure 15).

\section{Stress measurements}

Vibrating wire stress gauges were installed in holes 10 and
14 when they were filled. These instruments show stress changes in a single plane. Two sets were installed in each hole. One set was mounted such that the subvertical and dip stresses were recorded (XZ) and the other in the plane of the subvertical and strike stresses (YZ). In this layout the following conventions apply: $\mathrm{X}$ is parallel to dip (parallel to hole axis, pointing down the hole); $\mathrm{Y}$ is parallel to the strike direction (horizontal, pointing east); and $\mathrm{Z}$ is $23^{\circ}$ down-dip of vertical (i.e. perpendicular to the hole axis and the horizontal strike direction).

The readings were processed so that the major $(\mathrm{P})$ and minor $(Q)$ principal stresses were calculated in the $\mathrm{XZ}$ and $\mathrm{YZ}$ planes. The measurement histories up to the boring of hole 19 are shown in Figure 16 (hole 10) and Figure 17 (hole 14).

The instruments show reasonable reactions to the drilling of nearby holes. Hole 10 shows a significant reaction to the drilling of the hole 14 pilot, and a similar reaction to the reaming of the hole. The boring of hole 17 had a small influence, while hole 18 caused significant stress change. Hole 14 also showed a relatively small reaction to hole 17 , and a significant change when hole 10 was bored. A portion of the XZ record from hole 14 was corrupted and not used in the analysis of this data. The high tensile stresses recorded in the XZ plane of hole 10 are also questionable.

A hole was drilled into the fill emplaced in hole 10 around four months after the completion of hole 18 (hole 24 was being bored at the time). Absolute stress measurements were done using the compact conical borehole overcore (CCBO) stress measurement method (Sugawara and Obara, 1999). The concrete core often broke up during overcoring, requiring repeated measurements. The measured strain changes were averaged to provide a complete stress tensor (Figure 18). The major principal stress is very close to strataperpendicular, the intermediate stress $\left(54 \%\right.$ of $\left.\sigma_{1}\right)$ is oriented approximately east-west (i.e. parallel to strike), and

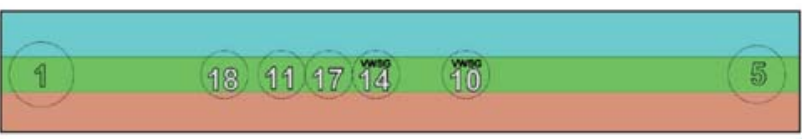

Figure 14-Detail of the holes at the west end of the test site

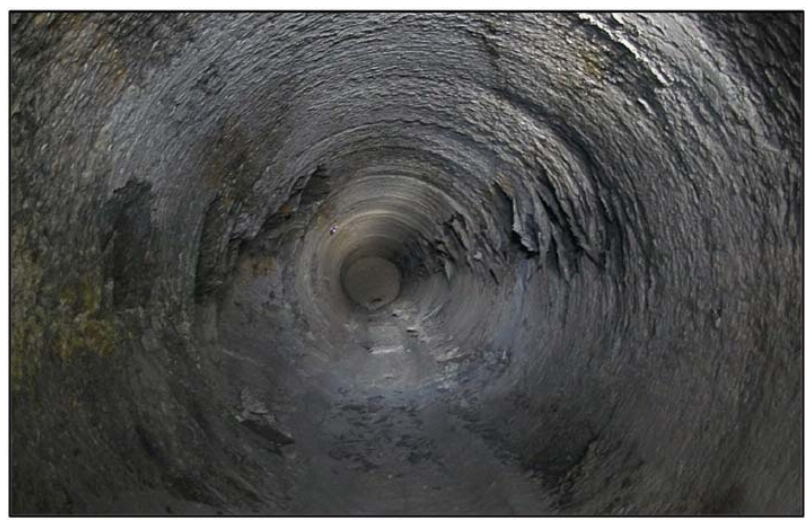

Figure 15-Photograph of hole 17 taken from the upper reef drive, showing spalling on the western (right) sidewall that occurred only after the hole 18 was drilled 


\section{Calibration of a numerical model for bore-and-fill mining}

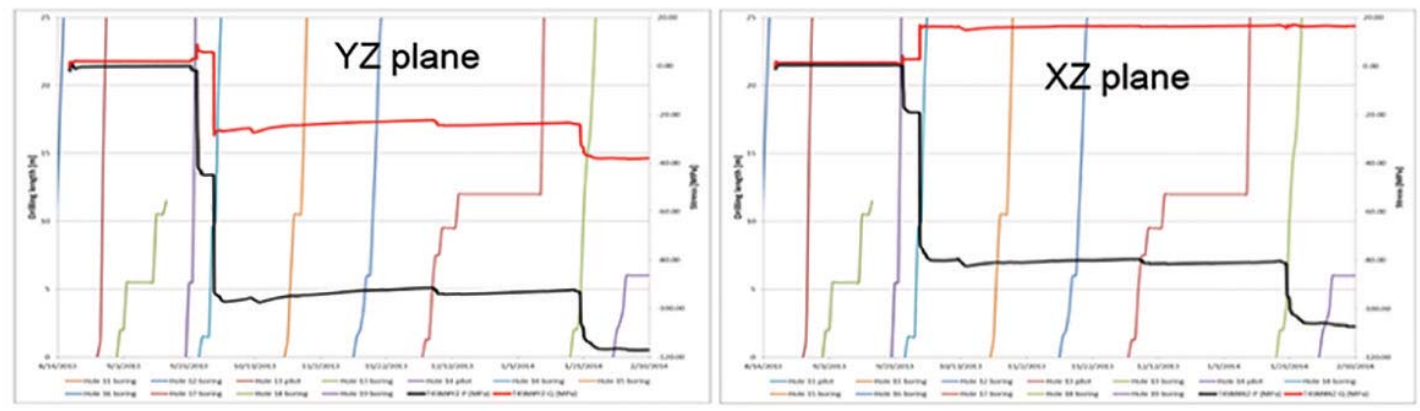

Figure 16-Stress change measurement history for hole 10

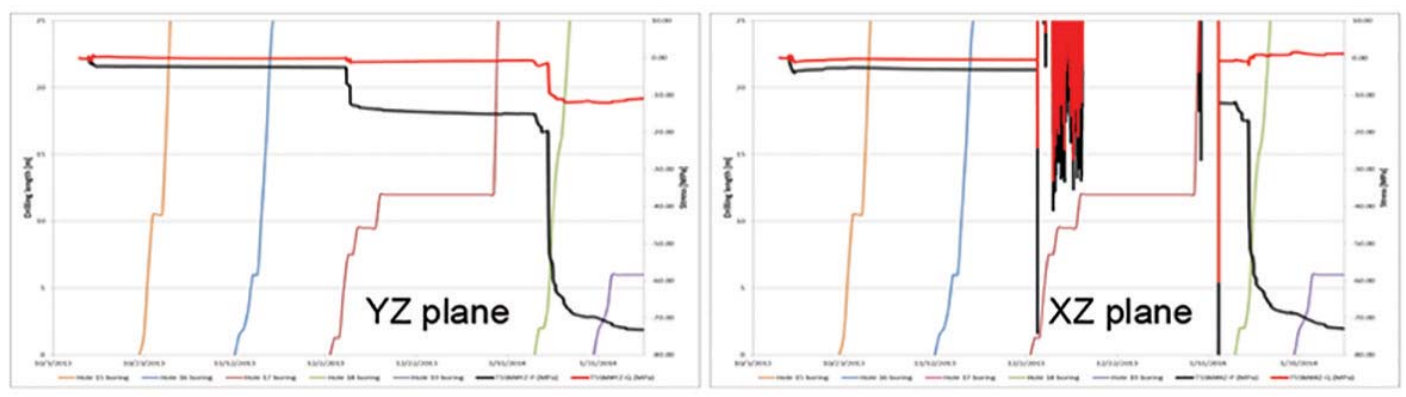

Figure 17-Stress change measurement history for hole 14

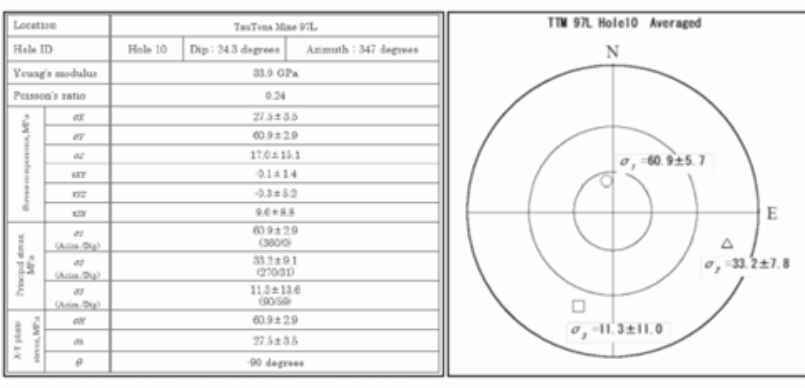

Figure 18-Averaged results from the 3D CCBO absolute stress measurements in hole 10

the minor stress is roughly parallel to dip. The minor stress has a particularly high uncertainty, ranging from 0.3 to $22.3 \mathrm{MPa}$.

The CCBO and VWSG measurements are discussed and compared with the model results in a later section.

Virgin stress conditions were estimated from the results of Map3D modelling of the shaft pillar area.

\section{Numerical modelling}

\section{Background}

Borehole breakout occurs when cylindrical holes are drilled in a pre-stressed rock mass. In an idealized triaxial stress field, where the intermediate principal stress is oriented parallel to the hole axis, high tangential shear stresses are developed along the borehole sidewalls oriented parallel to the minor principal stress axis. Failure will either take the form of conjugate fracture zones which intersect at some distance from the borehole wall (Haimson and Song, 1993), or extensile fracturing sub-parallel to the borehole wall and parallel to the major compressive stress direction (Ewy and Cook, 1990; Lee and Haimson, 1993; Sellers and Klerck, 2000). The former results in wedge-shaped fallout bounded by shear fractures, and generally occurs in weak sedimentary rocks. The latter is typical in strong brittle rocks, and has the appearance of buckled slabs that spall away from the free face. This type of extensile fracturing is typically observed around deep-level gold mining excavations (Ortlepp, 1997). Tensile and 'remote' fractures may also occur, depending on the magnitude of the confining stress (Carter, Lajtai, and Yuan, 1992), although these are not expected for isolated holes at depth (Roberts, 2001).

Breakout around a large-scale underground excavation was studied in detail at the AECL Mine-by experimental tunnel (Read, 1994; Martin and Read, 1996; Martin, 1997). Hajiabdolmajid, Kaiser, and Martin (2002) successfully simulated damage around the Mine-by tunnel using a cohesion-weakening and frictional-strengthening strainsoftening (CWFS) model implemented in the FLAC program (Figure 19). The model was implemented using user-defined FISH functions. This model has subsequently been implemented in the main FLAC and FLAC3D codes.

Sellers and Klerck (2000) performed tests on cubes of quartzite and norite containing a cylindrical hole drilled halfway through the samples. Solid and layered samples were tested. They were able to replicate the fractures observed in the tests using a Mohr-Coulomb strain-softening discrete fracture algorithm implemented in the Elfen finite/discrete element code. It was found that the presence of layers significantly altered the fracture patterns, resulted in more fracturing than was observed in the solid blocks (Figure 20). The fracturing also tended to be constrained by the layers, that is, fractures did not penetrate through the layer boundaries. 


\section{Calibration of a numerical model for bore-and-fill mining}
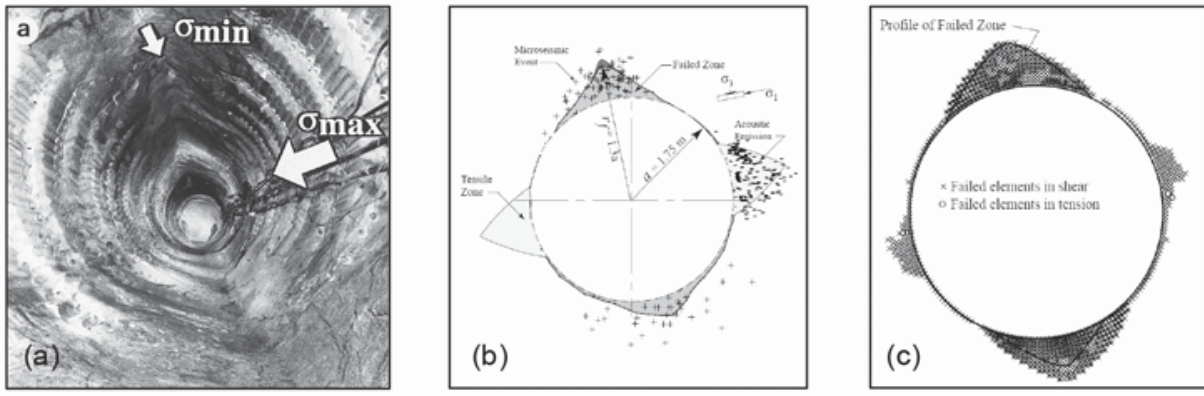

Figure 19-(a) Photograph of the shape of the failed zone observed around the circular test tunnel (after Martin, 1997), (b) schematic showing microseismic events locations in the notch area (+), and acoustic emission locations (-) in the tensile failure zone, and (c) damage predicted by the CWFS model (after Hajiabdolmajid, Kaiser, and Martin, 2002)

The literature suggests that a Mohr-Coulomb strainsoftening (CWFS) model will accurately model the extent of damage around circular holes in a biaxial stress field. Sellers and Klerck (2000) showed that the presence of contact planes influences the fracturing, tending to constrain the damage between these planes. This was also observed between CLR contacts at the pilot site. The model should be able to replicate this trend.

\section{Modelling approach}

Initial modelling with FLAC did not produce satisfactory results. The fracture patterns around the hole tended to follow the rectilinear mesh (Figure 21) and did not resemble the natural breakout patterns shown above (Figure 19 and Figure 20). The mesh structure, command syntax, and FISH implementation of FLAC and FLAC3D differ significantly. Since the intention was ultimately to extend the modelling work into three dimensions, it was decided that it would be more efficient to use FLAC3D to construct and analyse all the models.

Plane strain modelling was done in FLAC3D by extruding 2D meshes made up of triangular zones into 3D prismshaped zones. The result is a model that is one element thick, with the zone thickness corresponding to the 2D zone edge length in the area of interest. Plane strain conditions were imposed by constraining all grid-points in the out-of-plane (z) direction. The CWFS (Mohr-Coulomb with strainsoftening) material model was used to simulate the failure around the holes. Interfaces were used to represent the CLR contacts.

All models are constructed on the same basic template. A solid square block of sufficient size is defined and a fine mesh zone (FMZ) is specified where failure is expected to occur. The block is meshed uniformly in the FMZ and the zone sizes gradually increased towards the boundaries. The model is assigned sliding constraints along three boundaries. A pressure load is applied along the top boundary corresponding to the major principal stress. The $x$ (horizontal) axis in these models corresponds with the strike of the reef. The $y$ axis is the upwards normal to the strata. This axis is offset from vertical by an angle equal to the dip of the strata. Initial stresses that correspond to the major and minor principal stresses are applied throughout the model. Gravity loading is not applied. Geometry features are included in a number of these models. Most commonly, a pair of horizontal lines representing the Carbon Leader contacts are specified. In other models, strata are defined in a similar way at regular spacings above and below the reef. In some of these models the hole profiles are also defined. Strainsoftening materials are specified in the FMZ and elastic materials elsewhere. The zones on either side of contact planes are separated and the planes are assigned MohrCoulomb strain-softening properties.

It was noted above that the extent of fracturing greatly exceeds the observed breakout volume. The model needs to replicate this observation. Fracturing in the CWFS model is expressed as the accumulation of so much plastic strain that the affected zones reach 'zero' (very low) cohesion. While it is intuitively attractive to remove and replace these failed zones with fill, such an approach will over-estimate the extent of breakout. A novel criterion is required to determine which zones should be removed to replicate the observed breakout.

As failure occurs around the periphery of the hole, the damaged material moves into the hole. The extent of this movement will decrease with distance from the surface of the hole. Examination of various displacement parameters indicated that the displacement contours resemble the shape of breakout observed underground. The magnitude of the displacement vector pointing into the hole and the displacement in a direction parallel to the minor stress (towards the hole centre) were examined as potential candidate criteria. It was found that the $x$-displacement contours quite closely mimic the typical breakout shape.

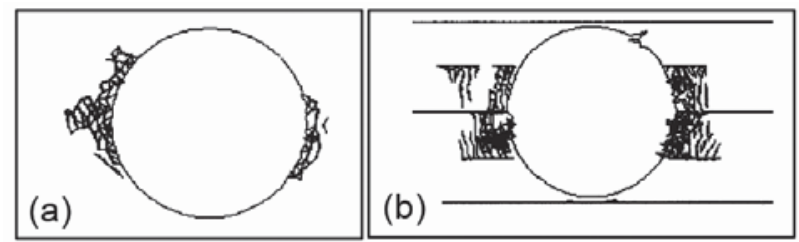

Figure 20-Modelled fractures for (a) solid and (b) layered blocks

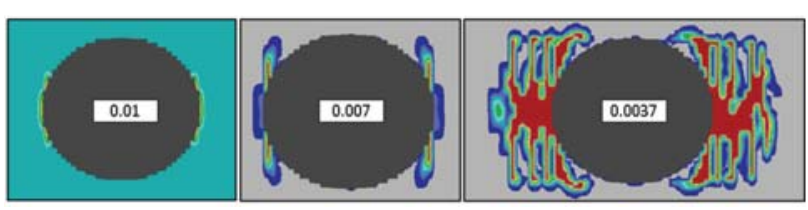

Figure 21-Plastic strain distributions for FLAC models assigned various values of strain-to-failure 


\section{Calibration of a numerical model for bore-and-fill mining}

Experimentation with these criteria and various other permutations (for example, zone deactivated if plastic strain and displacement criterion are exceeded) showed that the displacement perpendicular to the major stress, expressed as a ratio of the distance to the centre of the hole, provided the best approximation of the breakout volume and shape. Absolute displacement in the same direction gave similar results, but the displacement ratio criterion allowed greater control, particularly at higher criterion values.

Table I shows how the breakout shape and volume vary with the value of the displacement ratio criterion. For a displacement ratio of $10^{-4}$, zones not involved in the breakout process are deactivated, which is not realistic. At a ratio of 5 $\times 10^{-4}$, the breakout resembles the extreme cases observed underground. This value represents a practical maximum value of breakout $\left(0.42 \mathrm{~m}^{3} / \mathrm{m}\right)$. The maximum observed breakout of $0.63 \mathrm{~m}^{3} / \mathrm{m}$ cannot be achieved with this material set or deactivation criterion. For ratios greater than 0.15 less breakout occurs than was observed, so this serves as an upper limit for this criterion. At a value of 0.29 no zones are deactivated. The criterion needs to be recalibrated for different property sets. The deactivation criterion is not, strictly speaking, a material property since its ideal value depends on the deformation mechanics of the model. It is nevertheless reasonable to assign different critical values to different materials.

The deactivation procedure is initiated after a stable solution is obtained by the FLAC3D 'unbalanced force ratio' criterion. After the zones are deactivated they are reinitialized and assigned the properties of the fill material in a single step. No timestepping occurs between deactivating the zones and reactivating them as fill.

It is essential that the filling procedure does not significantly alter the stress distribution around the hole, or induce significantly more damage during subsequent cycling. An algorithm was developed that averages the stress components in the zones that are to be deactivated. These averaged stresses are applied as initial stresses in all fill zones when these zones are reactivated. This algorithm resulted in a less disturbed stress distribution than applying zero stress in the fill zones. Further experimentation revealed that applying a factor to the averaged stresses was even more effective in reducing the stress disturbance. The optimal factor for the models discussed in this paper was -0.1 . This equates to the application of a small tensile stress within the fill.

\section{Calibration}

The unknown parameters in this study include the internal cohesion, internal friction angle, and plastic strain-to-failure of the hangingwall, footwall, and CLR strata. The properties of the contacts between the CLR and surrounding quartzites

\section{Table I \\ Breakout shapes and volumes for various critical displacement ratios using material property set S1}

\begin{tabular}{|l|c|c|c|c|}
\hline $\begin{array}{l}\text { Displacement } \\
\text { ratio }\end{array}$ & 0.0001 & 0.005 & 0.008 & 0.015 \\
\hline $\begin{array}{l}\text { Removed volume } \\
\left(\mathrm{m}^{3} / \mathrm{m}\right)\end{array}$ & 0.52 & 0.215 & 0.136 & 0.044 \\
\hline Breakout shape & & 0 & 0 & 0 \\
\hline
\end{tabular}

will also affect the extent of failure and breakout. The initial assumed rock mass material properties were obtained from back-analysis of laboratory experiments by Roberts (2012). The strength (cohesion) was reduced to between 48 and 58\% of laboratory values, in accordance with York (1998), to represent in situ rock mass properties. For the contact planes, Sellers and Klerck (2000) used a friction angle of $30^{\circ}$ (and zero cohesion) between rock layers to simulate laboratory experiments.

The deviation of some of the holes into the surrounding quartzites provided valuable data that could be used to calibrate material properties and contact parameters. Based on the measured breakouts and observed fracturing the calibration criteria in Table II are used.

For the geology shown in Figure 12, fracturing extending one hole diameter away from the edge of the borehole is expected. The breakout volume for this hole is not known, but is assumed to be typical $\left(0.08\right.$ to $\left.0.12 \mathrm{~m}^{3} / \mathrm{m}\right)$. A model was created to simulate the damage around this hole. The photographs were digitized and the strata positions traced to replicate these contacts as accurately as possible.

The resulting cohesion distribution using set $x R$ model parameters is shown in Figure 22. The extent of fracturing is similar to that observed underground. Penetration of the fractures into the stratum below the CLR is also replicated, particularly further away from the hole. The 'onion-skin' nature of the fractures is not replicated in the model. Fractures form a lattice that we would more typically expect to see in 2D models of pillar fracturing. This is a feature of this implementation of Mohr-Coulomb strain softening. As noted above, the intention here is not to precisely replicate the shape of the fracturing, but to match the extent of fracturing so that the resulting stress redistribution and deformation are simulated.

Modelling the strata around this hole with various material and contact property sets provided simple guidelines for further calibration. It was found necessary to reduce the

Table II

\section{Calibration criteria}

\begin{tabular}{|l|c|c|}
\hline Scenario & $\begin{array}{c}\text { Minimum } \\
\text { breakout }\left(\mathrm{m}^{3} / \mathrm{m}\right)\end{array}$ & $\begin{array}{c}\text { Maximum } \\
\text { breakout }\left(\mathrm{m}^{3} / \mathrm{m}\right)\end{array}$ \\
\hline $\begin{array}{l}\text { Isolated hole in a single material } \\
\text { (hangingwall or footwall) }\end{array}$ & 0.02 & 0.06 \\
\hline $\begin{array}{l}\text { Isolated hole in centre of reef } \\
\begin{array}{l}\text { Isolated hole with top contact } \\
\text { coinciding with top of hole }\end{array}\end{array}$ & 0.04 & 0.18 \\
\hline $\begin{array}{l}\text { Isolated hole with top contact } \\
\text { coinciding with bottom of hole }\end{array}$ & 0.04 & 0.20 \\
\hline $\begin{array}{l}\text { Elsewhere, including locations } \\
\text { where the bottom contact } \\
\text { coincides with bottom of hole }\end{array}$ & 0.02 & 0.13 \\
\hline
\end{tabular}
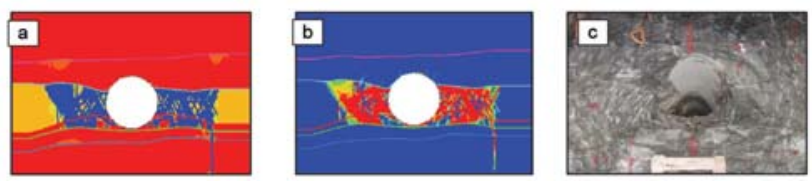

Figure 22-Internal cohesion (a) and maximum plastic shear strain (b) for the 'exact' model using set xR parameters, compared to fracturing observed underground (c) 


\section{Calibration of a numerical model for bore-and-fill mining}

CLR internal friction angle from that of the host rock (from $48^{\circ}$ to $40^{\circ}$ ) to obtain the extent of fracturing observed. The damage could not be matched by reducing UCS, tensile strength, or plastic strain-to-failure. It was necessary to include contacts. Without contacts, even greatly weakening the CLR material properties did not result in a degree of fracturing similar to that observed. It was found that a minimal value of contact cohesion $(0.5 \mathrm{MPa})$ on all contacts produced the best approximation to the observed fracturing. Appropriate values for contact friction were generally quite low $\left(15-30^{\circ}\right)$ relative to those previously employed in the literature.

With these basic features of the fracturing and breakout successfully approximated, more detailed features observed at the pilot site were used to fully calibrate the model.

The effect of the vertical hole position was examined by varying the hole position relative to the CLR stratum in a standard model. The intention was to match the trends evident in Figure 10. In this model, only the top and bottom CLR contacts were modelled. Experiments with multiple strata contacts in the footwall and hangingwall showed that excessive breakout and failure occurred unless the contacts were exceptionally strong $\left(\varnothing>45^{\circ}, C_{0}>5 \mathrm{MPa}\right)$. They are therefore treated as 'welded' and not modelled as interfaces. Given the asymmetry in the response when the hole approaches the upper and lower CLR contacts, different properties are assigned to these, with the upper contact expected to be weaker or to have a lower friction angle.

In this model the hole is not predefined and can be bored at any position in the model FMZ. To assess the variability imposed by the underlying mesh geometry, the model was run with the hole placed randomly. The resulting distribution of breakout volume as a function of vertical $(y)$ position is shown in Figure 23. The expected envelope of breakout volumes observed underground is included in the vertical position graph.

Most of the breakout values fall within the expected envelope for the vertical position graph. The breakout where the hole bottom coincides with the upper contact slightly exceeds the expected maximum, and the lowest values tend to be lower than the expected minimum of $0.02 \mathrm{~m}^{3} / \mathrm{m}$. Some variability is evident, as holes with similar elevations show different breakout levels. In the 'typical' range $\left(0-0.06 \mathrm{~m}^{3} / \mathrm{m}\right)$ this variability can be as high as $0.02 \mathrm{~m}^{3} / \mathrm{m}$.

The material models and contact properties given for property set 88 (upper CLR: $\emptyset=40^{\circ}, C_{0}=0.5 \mathrm{MPa}$, lower CLR: $\emptyset=30^{\circ}, C_{0}=0.5 \mathrm{MPa}$ ) were used in the subsequent modelling.

\section{Fill properties}

The fill material was extensively tested using specimens prepared in a laboratory setting and core obtained from fill emplaced in holes at the pilot site. The resulting average material properties are given in Table III.

The plastic strain at which the minimum cohesion is attained (plastic strain-to-failure) was set to the same value as the rock mass.

\section{Modelling of the 10-11-14-17-18 hole sequence at Tau Tona}

\section{Model set-up}

The holes in this sequence are shown in Figure 24. It is evident that the holes deviate significantly from the reef package, and are not consistently parallel. Cross-sections (along strike) at different positions result in very different geometries along the length of the holes.

The 3D model in Figure 24 was cut through by a series of planes oriented approximately perpendicular to the hole axes and spaced $1.5 \mathrm{~m}$ apart over the length of the hole. The individual slice geometries were meshed in two dimensions and analysed using the calibrated properties obtained above. Recall that hole 17 was half-filled from the southern (lower) reef drive. The hole was therefore not filled in the models representing the upper half of the hole profiles.

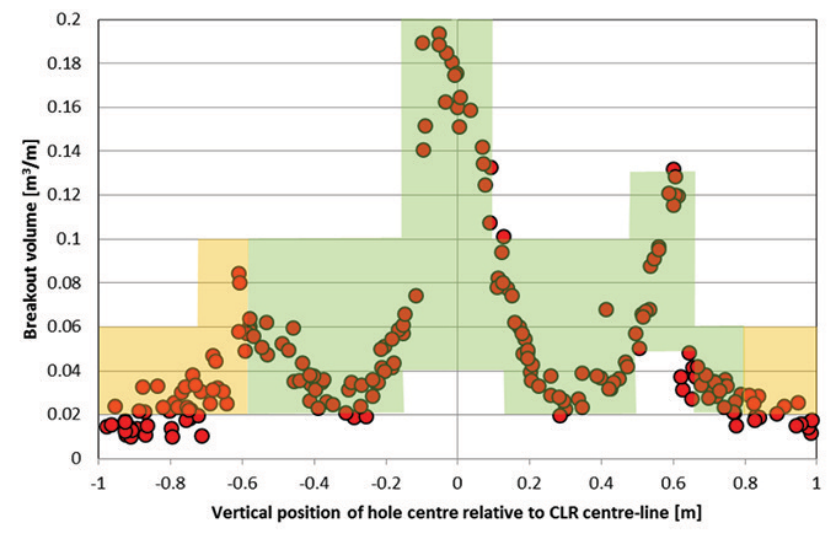

Figure 23-Effect of vertical position on the breakout volume for property set S8

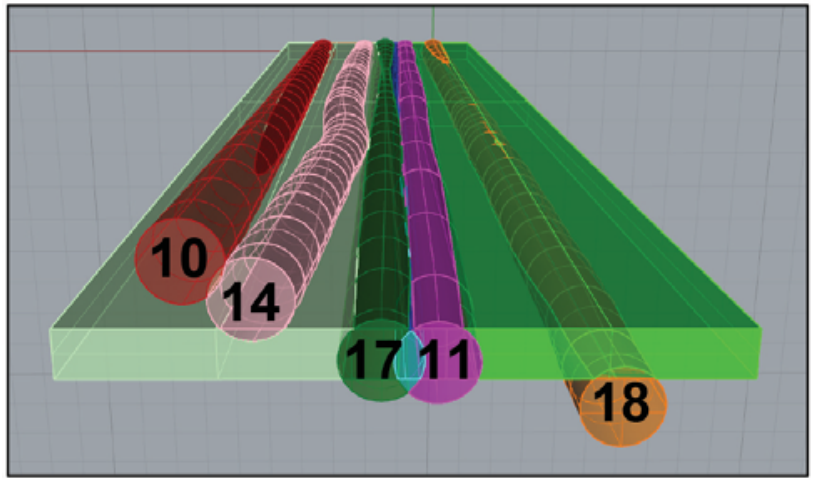

Figure 24-Perspective view of holes $10,11,14,17$, and 18 relative to the reef package, viewed from the northern reef drive

Table III

Fill material properties

\begin{tabular}{l|l}
\hline Property & Value \\
\hline Young's modulus & $34.6 \mathrm{GPa}$ \\
\hline Poisson's ratio & 0.24 \\
\hline Density & $2160 \mathrm{~kg} / \mathrm{m}^{3}$ \\
\hline Initial cohesion & $30 \mathrm{MPa}$ \\
\hline Minimum cohesion & $0.1 \mathrm{MPa}$ \\
\hline Initial friction angle & $35^{\circ}$ \\
\hline Maximum friction angle & $40.4^{\circ}$ (at one-tenth of maximum plastic strain) \\
\hline Maximum dilation angle & $10^{\circ}$ \\
\hline Tensile strength & $9.9 \mathrm{MPa}$ \\
\hline
\end{tabular}




\section{Calibration of a numerical model for bore-and-fill mining}

\section{Results}

The distribution of breakout and damage along the length of the holes is now examined in detail. In the following discussion, 'length' refers to distance from the southern reef drive. The coloured regions indicate material that has been replaced with fill at the end of the relevant stage and correspond with the hole profile plus the expected breakout. The colours in each stratum (CLR, hangingwall, and footwall) also vary as the filling algorithm assigns filled groups according to the rock mass group to which the material originally belonged.

\section{Hole 10}

Hole 10 is an isolated hole that deviates upwards so that it lies entirely in the hangingwall at the northern reef drive. At this point the bottom of the hole is around $200 \mathrm{~mm}$ above the upper reef contact. The modelled and observed distributions of breakout volume are compared in Figure 25. Table IV compares the breakout shapes. The largest modelled breakouts occur when the hole is in the centre of the reef and the upper contact coincides with hole bottom. This conforms to expected behaviour (Figure 23) but appears to be offset (in terms of the length axis) from the underground scan data. Lower modelled breakouts occur when the hole is located in the hangingwall, as observed in the scans. The breakout shapes show similar trends, but there is a mismatch at 12 to $18 \mathrm{~m}$. It appears that the actual hole is no longer influenced by the reef contact, while the modelled breakout is clearly affected and reaches a maximum at this point. This is due to the positions of the actual and modelled holes (relative to the CLR contact) being slightly different. Shifting the model result to the left gives much better parity.

\section{Hole 11}

Hole 11 is far enough from hole 10 to ensure that induced stresses will be low, and therefore little additional breakout is expected. The hole is located in the reef package for its entire length, so a reasonably uniform distribution of breakout is expected. This is confirmed in Figure 26. The average breakout is $0.10 \mathrm{~m}^{3} / \mathrm{m}$. This hole was not scanned, so no data is available for comparison.

\section{Hole 14}

Hole 14 is bored initially between holes 10 and 11 and then deviates upwards and towards hole 10 . The hole follows an
S-curve as it moves slightly away from hole 10 and then abruptly curves towards it and deviates sharply upwards. The modelled and observed distributions of breakout volume are compared in Figure 27. Breakout shapes are compared in Table V. The observed breakout is quite variable initially, and tends to become limited to the western sidewall when the distance to hole 14 reduces. The model shows the opposite trend, with more breakout in the damaged eastern sidewall. It appears that the deactivation algorithm is allowing too much breakout in the hangingwall layer. The critical displacements in the different material layers are not well calibrated for this particular situation.

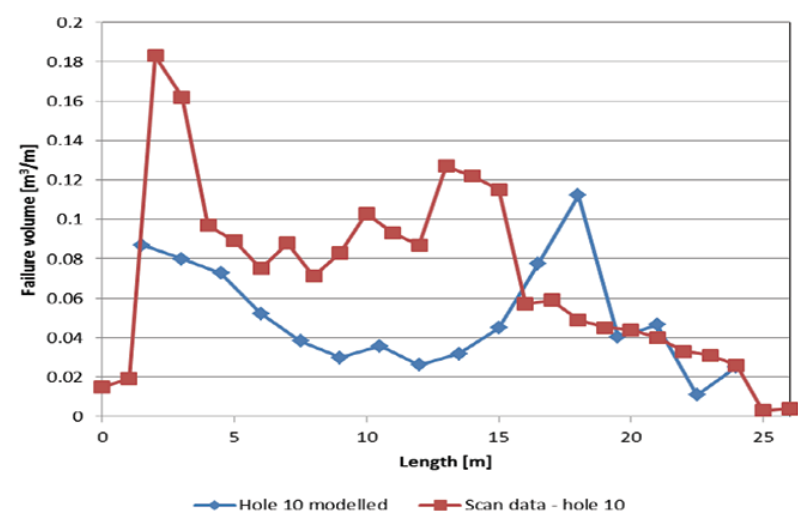

Figure 25-Observed and modelled distribution of breakout volume along the length of hole 10

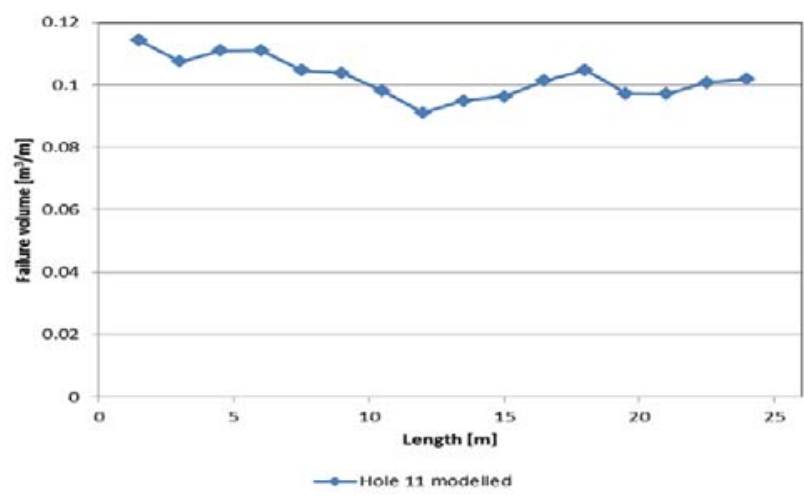

Figure 26-Modelled distribution of breakout volume along the length of hole 11

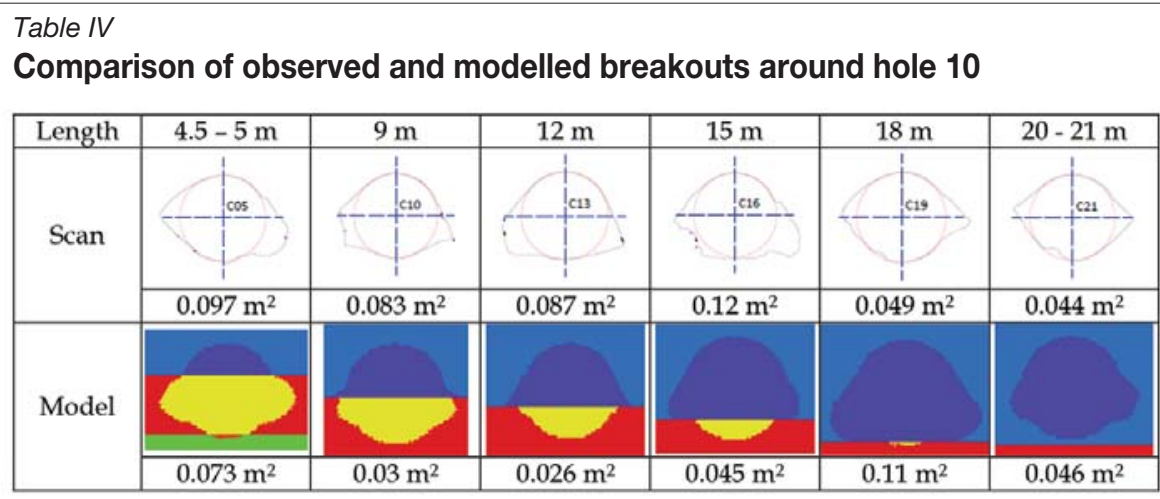




\section{Calibration of a numerical model for bore-and-fill mining}

\section{Hole 17}

In reality and in the models, hole 17 shows breakout only towards the top of the hole, where the distance between holes 17 and 14 increases sufficiently for breakout to occur.

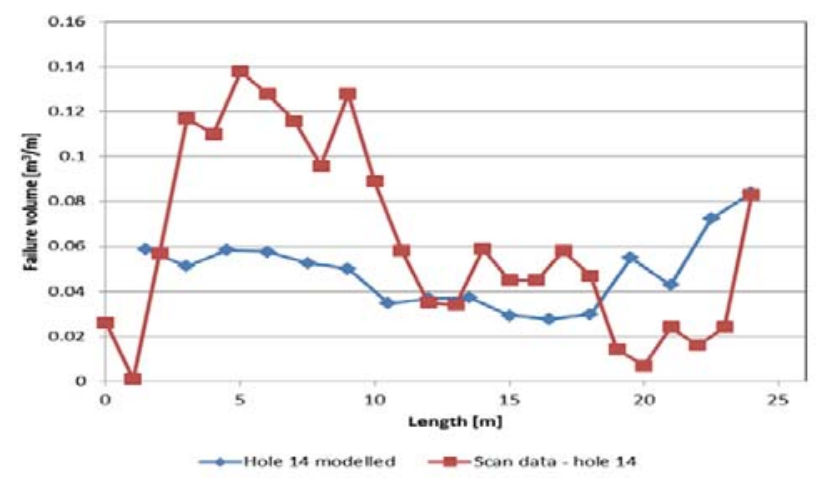

Figure 27-Observed and modelled distribution of breakout volume along the length of hole 14

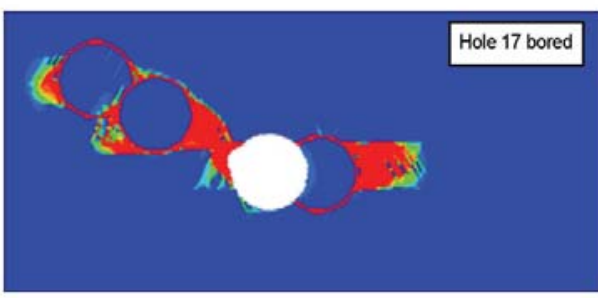

Figure 28 shows that damage occurs in the western side of the unfilled hole 17 when hole 18 is drilled, as was observed on site (Figure 15).

\section{Hole 18}

Hole 18 is bored in the highly stressed region adjacent to hole 11 . The hole dips into the footwall, gradually at first and then, from around $21 \mathrm{~m}$ length, quite abruptly. The gap to hole 11 increases from zero to about $0.8 \mathrm{~m}$ at the northern reef drive.

Figure 9 shows the distribution of breakout extents and the breakout shapes along the length of the hole. Breakouts are compared in Table VI and Figure 29.

Breakout around hole 18 shows a general increase from the southern drive up to a maximum at $12 \mathrm{~m}$ by observation, and at $22 \mathrm{~m}$ in the model. As the distance between the holes increases, the breakout volume increases up to the point where the hole dips down rather abruptly into the footwall, whereupon the hole straddles the lower reef contact and breakout volume decreases. The observed and modelled

Figure 28-The appearance of damage in the fill in the sidewall of hole 17 after hole 18 is bored (northernmost model)

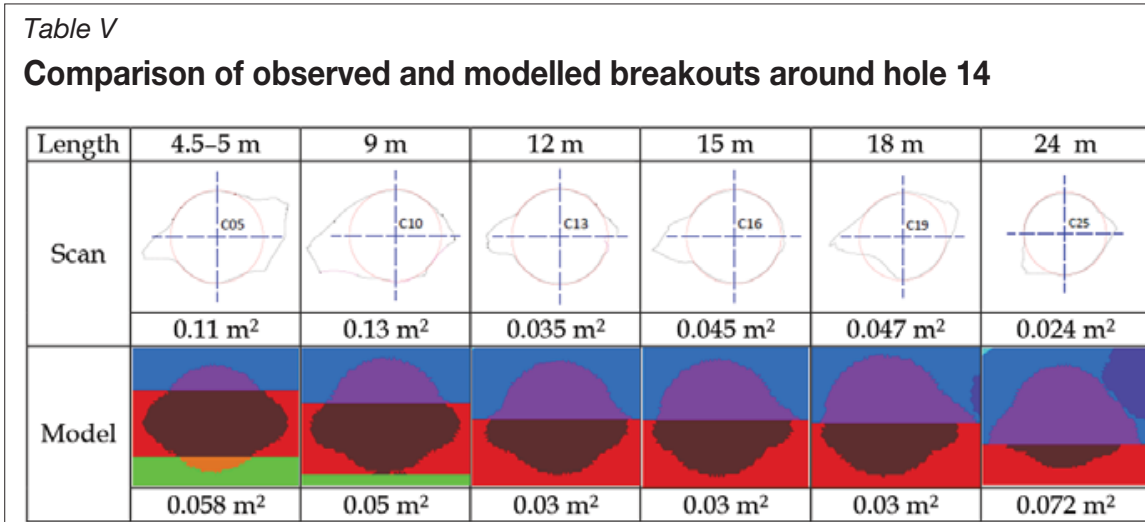

Table VI

Comparison of observed and modelled breakouts around hole 18

\begin{tabular}{|c|c|c|c|c|c|}
\hline Length & $4.5-5 \mathrm{~m}$ & $9-10 m$ & $12 \mathrm{~m}$ & $15 \mathrm{~m}$ & $18 \mathrm{~m}$ \\
\hline \multicolumn{6}{|l|}{ Scan } \\
\hline & $0.12 \mathrm{~m}^{2}$ & $0.17 \mathrm{~m}^{2}$ & $0.29 \mathrm{~m}^{2}$ & $0.11 \mathrm{~m}^{2}$ & $0.07 \mathrm{~m}^{2}$ \\
\hline \multicolumn{6}{|l|}{ Model } \\
\hline & $0.087 \mathrm{~m}^{2}$ & $0.11 \mathrm{~m}^{2}$ & $0.11 \mathrm{~m}^{2}$ & $0.14 \mathrm{~m}^{2}$ & $0.07 \mathrm{~m}^{2}$ \\
\hline
\end{tabular}




\section{Calibration of a numerical model for bore-and-fill mining}

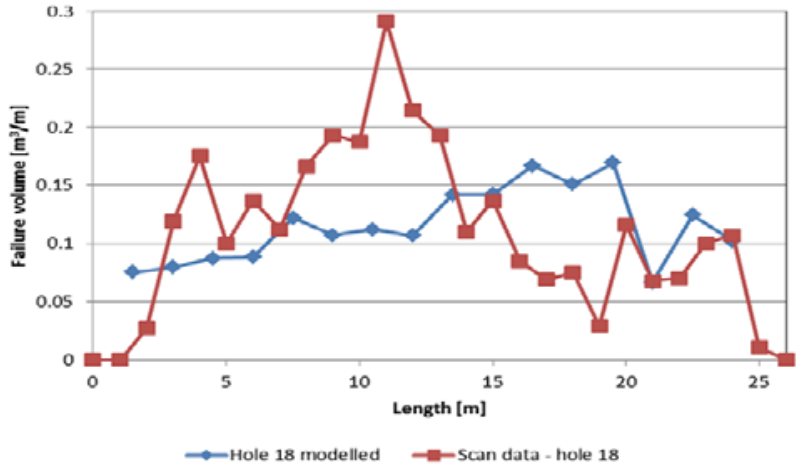

Figure 29-Observed and modelled distribution of breakout volume along the length of hole 18

breakout shapes are generally very similar, but the magnitudes differ, particularly when the hole dips.

\section{Stress measurement comparison}

The stresses measured by the VWSGs are compared with modelled stresses in Figure 30. In these graphs the major measured stresses from each VWSG pair are averaged. The principal measured stresses were oriented approximately on dip, on strike, and perpendicular to the reef plane, which allows us to compare the $x x, y y$, and $z z$ stresses directly with the measured stresses. CCBO measurements are shown in the graph for hole 10 .

In hole 10, the measured subvertical (reef-perpendicular: yy) stresses are up to $35 \mathrm{MPa}$ higher than those modelled. Both the model and VWSGs give higher stresses than the CCBO measurement: the CCBO reading is around half that of the VWSG. The strike stresses $(x x)$ show better correlation, differing by only $3.7 \mathrm{MPa}$ in the final stage. These values approximately correspond with the lower error bracket of the CCBO reading. The dip stress $(z z)$ according to the VWSG is tensile, while the $\mathrm{CCBO}$ and model results indicate compressive stresses of up to $22.3 \mathrm{MPa}$ and $25.4 \mathrm{MPa}$, respectively. All components in hole 14 are reasonably well matched, but the subvertical $(y y)$ stress measured in response to the boring of hole 18 is much greater than that modelled.

\section{Closure}

The deformation in response to the boring of holes is expressed as closure. Closure provides a measure of the extent to which the surrounding rock mass is disturbed by the mining operation and, as a relative measure, indicates the potential for seismic energy release. Closure in this instance is measured as the change in $y$ displacement at horizons 1.5 $m$ above and below the reef centreline. This envelope was chosen as it corresponds to the height of the reef drives at either end of the holes. The closures at the southern and northern reef drives were extracted from the model results and are presented in Figure 31. Both histories show the greatest increases in closure over stages where significant failure occurs. For example, after boring hole 14 the rock mass spanning all holes (plus the fractured zone around holes 10 and 11) has failed.

\section{Discussion}

The extent of simulated breakout is generally consistent with that observed underground; however, the distribution of breakout along the length of the hole is not faithfully replicated. The effect of the vertical position of the hole is clearly discernible in the results, as is the increased fallout volume and asymmetric breakout around the more highly stressed hole (hole 18). The absence of fallout in the hole bored between filled holes (hole 17) is also replicated, with damage occurring later when the adjacent hole was bored. The differences in breakout volume are partially explained by the variability of the geology and differences in the relative positioning of the holes.

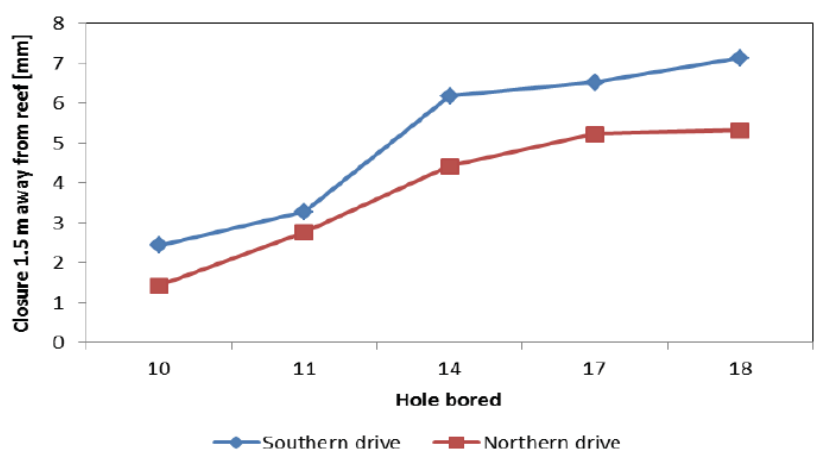

Figure 31-Maximum closure measured between horizons $1.5 \mathrm{~m}$ above and below the reef drive

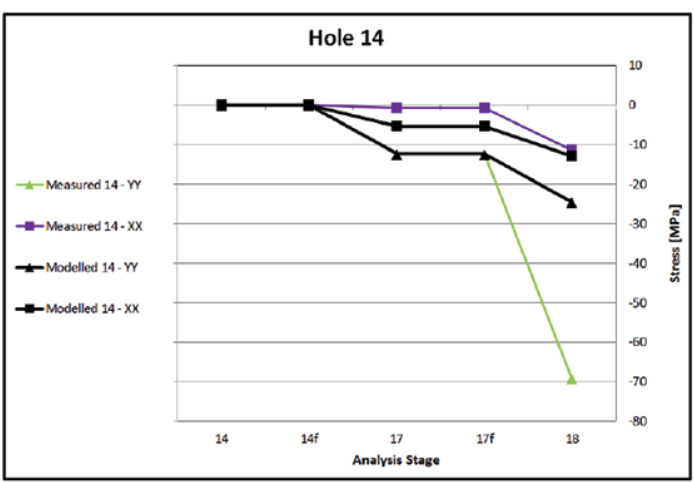

Figure 30-Comparison between modelled and measured stress readings in holes 10 and 14. Error bars show the range of values obtained by CCBO measurements for each component 


\section{Calibration of a numerical model for bore-and-fill mining}

The correlation between measured and simulated stresses was inconsistent. The VWSG-measured dip stresses were tensile, which does not correspond with the modelled stresses or those measured by CCBO. The strike stresses were in reasonable agreement with the measured stresses. Strataperpendicular stresses measured by VWSG were higher than those modelled, and both were higher than those measured using CCBO. The measured subvertical and strike stress changes correspond well with the boring of nearby holes, but the measured magnitude of the subvertical changes appears to be higher than the modelled value. Stresses within the models varied considerably: from $131 \mathrm{MPa}$ to $47 \mathrm{MPa}$ in hole 10 . Shifting the position of the measurement to the west in the model would give values much closer to those measured with the VWSGs, while shifting the position to the east would give values closer to the $\mathrm{CCBO}$ measurements. For the purposes of forward modelling it is sufficient that the stress gradient captures both the maximum and minimum values indicated by the instruments.

Closure histories showed that closure increases with the effective excavated span. The closure increases most abruptly when large volumes of rock mass fail. The decreasing closure increments indicate that the system is becoming more stable. Even when a hole (18) is drilled outside of the filled region, the closure increment is small compared to the increments recorded while creating the initial span (10-11-14).

The correlations obtained here are believed to be sufficient for forward modelling. It is re-emphasized that the breakout deactivation algorithm is not suitable for general use, and needs to be calibrated according to the context in which it is to be used.

\section{Conclusions}

A pseudo-3D model for simulating drill-and-fill operations on the Carbon Leader Reef was calibrated against underground data and used to successfully replicate the damage and observations around a selected sequence of holes at the 97 level test site. Sequencing of the holes, the resulting geometry of the holes and pillars, and the local geological and material characteristics, had a significant influence on the occurrence of damage and stress redistribution.

A novel displacement-based method for simulating breakout was developed for use on Carbon Leader models. Although the breakout distributions were not precisely matched, the modelled values lay within the extremes that were observed. Other features, such as the additional damage that occurred in the fill around hole 17 after boring hole 18, were replicated. Asymmetrical breakout was replicated around hole 18, but not around hole 14, where the critical displacement values appeared not to be well calibrated.

Modelled stresses and measured stress histories showed similar trends, but the magnitudes differed by varying degrees in each stress component. The modelled subvertical stresses were generally lower than those measured by vibrating wire stress gauge (VWSG), although both were greater than that obtained from a compact conical borehole overcore $(\mathrm{CBO})$ measurement. Either measured value could be obtained by simply shifting the measurement position in the model. The strike stresses correlated reasonably well. Dip stresses were very different: tensile stresses were indicated by the VWSGs, and comparable compressive stresses by
CCBO and by the model. Since there is no obvious mechanism for generating tensile stresses in this situation, it is suggested that the VWSG reading for this component be discounted.

Further work will focus on implementing the systems described here in a fully three-dimensional model. Variations in the out-of-plane (dip) stress and geometry can then be accounted for. A more thorough set of sensitivity analyses will be done and forward modelling will be employed (in 2D and 3D) to determine the optimal extraction sequence and fill parameters.

\section{Acknowledgements}

The authors wish to thank the Tau Tona reef-boring team, rock engineering staff, surveyors, and management for their assistance. Thanks to Willie Timmerman, Johann de Wett, and Henry Klopper at African Consulting Surveyors for their diligence in creating and processing the scans; to Chris Stander and Willie Janse van Rensburg for their assistance underground; to the ATIC team for their assistance and support; to George Kgori for drilling a special hole; to Gerhard Hofmann for assisting with stress measurements and interpretations; to Roelize Nel for assistance with seismic interpretation; to Lourens Scheepers for his guidance and leadership; and to Shaun Newberry and AngloGold Ashanti for permitting publication of this information.

\section{References}

ADAms, G.R. 1978. A study of the fractures forms in the rock around openings made by a reef boring machine. Research report no. 60/78. Chamber of Mines Research Organisation, Johannesburg.

CARTER, B.J., Lajtai, E.Z., and YuAn, Y. 1992. Tensile fracture from circular cavities loaded in compression. International Journal of Fracturing, no. 57. pp. 221-236.

Ewy, R.T. and Соок, N.G.W. 1990a. Deformation and fracture around cylindrical openings in rock - I: Observations and analysis of deformations. International Journal of Rock Mechanics and Mining Sciences \& Geomechanics Abstracts, vol. 27. no. 5. pp. 387-407.

Ewy, R.T. and Соок, N.G.W. 1990b. Deformation and fracture around cylindrical openings in rock - II: Initiation, growth and interaction of fractures. International Journal of Rock Mechanics and Mining Sciences \& Geomechanics Abstracts, vol. 27. no. 5. pp. 409-427.

Haimson, B. and Song, I. 1993. Laboratory study of borehole breakouts in cordova cream: a case of shear failure mechanism. International Journal of Rock Mechanics and Mining Sciences \& Geomechanics Abstracts, vol. 30, no. 7. pp. 1047-1056.

Hajiabdolmajid, V., KaISER, P.K., and Martin, C.D. 2002. Modelling brittle failure of rock. International Journal of Rock Mechanics and Mining Sciences, vol. 39. pp. 731-741.

Hofmann, G., ScheEpers, L., and Ogasawara, H. 2013. Loading conditions of geological faults in deep level tabular mines. Proceedings of the 6 th International Symposium on In Situ Rock Stress, Sendai. Japan, 20-22 August, 2013. International Society for Rock Mechanics.

JAGER, A.J., WESTCOTT, M., and СоoK, N.G.W. 1975. A geological assessment of the applicability of reef boring to mining the Basal, Carbon Leader and Vaal Reefs. Research report no. 20/75. Chamber of Mines Research Organisation, Johannesburg. 


\section{Calibration of a numerical model for bore-and-fill mining}

KLERCK, P.A. 2000. The finite element modelling of discrete fracture in quasibrittle materials. PhD thesis, University of Wales. Swansea.

LEE, M. and Haimson, B. 1993. Laboratory study of borehole breakouts in Lac $\mathrm{du}$ Bonnet granite: a case of extensile failure mechanism, International Journal of Rock Mechanics and Mining Sciences \& Geomechanics Abstracts, vol. 30, no. 7. pp. 1039-1045.

MARTIN, C.D. 1997. The effect of cohesion loss and stress path on brittle rock strength. Canadian Geotechnical Journal, vol. 34. pp. 698-725

MARTIN, C.D. and READ R.S. 1996. AECL's Mine-by experiment: a test tunnel in brittle rock. Proceedings of the 2nd North American Rock Mechanics Symposium, Montreal. Vol. 1.. Aubertin, M., Hassani, F., and Mitri, H. (eds). A.A. Balkema, Rotterdam. pp. 13-24.

MURPHY, S.K. 2012. Linear elastic numerical modelling for failure prediction an assessment. Journal of the Southern African Institute of Mining and Metallurgy, vol. 112, no. 8. pp. 737-748.

ORTLEPP, W.D. 1997. Rock Fracture and Rockbursts: an Illustrative Study. Monograph Series M9. South African Institute of Mining and Metallurgy, Johannesburg.

READ, R.S. (1994). Characterizing excavation damage in highly stressed granite at AECL's Underground Research Laboratory. Proceedings of the International Conference on Deep Geological Disposal of Radioactive
Waste. Winnipeg, Toronto. Martino, J.B. and Martin, C.D. (eds). Canadian Nuclear Society. pp. 35-46.

ROBERTS, D.P. 2001. The influence of tunnel shape on damage and fracture propagation at ultra-depth. Proceedings of the Fourth International Conference of Discontinuous Deformation, University of Glasgow, June 2001. University of Glascow. pp 35-46.

RoBERTS, D.P. 2012. Numerical simulation of shear fracture evolution in laboratory-scale samples. Journal of the Southern African Institute of Mining and Metallurgy, vol. 112, no. 8. pp. 685-695.

SelLers, E.J. and KleRCK, P.A. 2000. Modelling of the effect of discontinuities on the extent of the fracture zone surrounding deep tunnels under pressure. Proceedings of the World Congress of International Tunnelling Association (ITA 2000), Durban, South Africa, 13-18 May 2000. Stacey, T.R. (ed.). Southern African Institute of Mining and Metallurgy, Johannesburg.

Sugawara, K. and OBARA, Y. 1999. Draft ISRM suggested method for in situ stress measurement using the compact conical-ended borehole overcoring (CCBO) technique. International Journal of Rock Mechanics and Mining Sciences, vol. 36. pp. 307-322.

YoRK, G. 1998. Numerical modelling of the yielding of a stabilizing pillar/foundation system and a new design consideration for stabilizing pillar foundations. Journal of the South African Institute of Mining and Metallurgy, vol. 98, October. pp. 281-297.

\section{APPENDIX}

\section{MATERIAL AND CONTACT PROPERTY SETS.}

\begin{tabular}{|c|c|c|c|c|c|c|}
\hline Material & Property & Set 1 & Set 3 & Set S8 & Set $x R$ & Set 9d \\
\hline \multirow[t]{11}{*}{ Quartzites } & Young's modulus [GPa] & 70 & 70 & 70 & 70 & 70 \\
\hline & Poisson's ratio & 0.25 & 0.25 & 0.25 & 0.25 & 0.25 \\
\hline & Density $\left[\mathrm{kg} / \mathrm{m}^{3}\right]$ & 2700 & 2700 & 2700 & 2700 & 2700 \\
\hline & Initial cohesion [MPa] & 28 & 28 & 28 & 28 & 28 \\
\hline & Minimum cohesion [MPa] & 0.1 & 0.1 & 0.1 & 0.1 & 0.1 \\
\hline & Initial friction angle & $40^{\circ}$ & $40^{\circ}$ & $40^{\circ}$ & $40^{\circ}$ & $40^{\circ}$ \\
\hline & Maximum friction angle & $48^{\circ}$ & $48^{\circ}$ & $48^{\circ}$ & $48^{\circ}$ & $48^{\circ}$ \\
\hline & Maximum dilation angle & $15^{\circ}$ & $15^{\circ}$ & $15^{\circ}$ & $15^{\circ}$ & $15^{\circ}$ \\
\hline & Tensile strength [MPa] & 10 & 10 & 10 & 10 & 10 \\
\hline & Maximum plastic strain & $2 \mathrm{e}-3$ & $2 e-3$ & $2 \mathrm{e}-3$ & $2 e-3$ & $2 e-3$ \\
\hline & $\begin{array}{l}\text { Deactivation criterion } \\
{[\mathrm{mm} / \mathrm{mm}]}\end{array}$ & $\mathrm{N} / \mathrm{A}$ & 0.003 & 0.003 & N/A & 0.003 \\
\hline \multirow{11}{*}{$\begin{array}{l}\text { Carbon } \\
\text { Leader } \\
\text { Reef (CL) }\end{array}$} & Young's modulus [GPa] & 70 & 70 & 70 & 70 & 70 \\
\hline & Poisson's ratio & 0.25 & 0.25 & 0.25 & 0.25 & 0.25 \\
\hline & Density $\left[\mathrm{kg} / \mathrm{m}^{3}\right]$ & 2700 & 2700 & 2700 & 2700 & 2700 \\
\hline & Initial cohesion [MPa] & 23 & 23 & 23 & 23 & 23 \\
\hline & Minimum cohesion [MPa] & 0.1 & 0.1 & 0.1 & 0.1 & 0.1 \\
\hline & Initial friction angle & $40^{\circ}$ & $35^{\circ}$ & $35^{\circ}$ & $35^{\circ}$ & $35^{\circ}$ \\
\hline & Maximum friction angle & $48^{\circ}$ & $40^{\circ}$ & $40^{\circ}$ & $40^{\circ}$ & $40^{\circ}$ \\
\hline & Maximum dilation angle & $15^{\circ}$ & $15^{\circ}$ & $15^{\circ}$ & $15^{\circ}$ & $15^{\circ}$ \\
\hline & Tensile strength [MPa] & 10 & 10 & 10 & 10 & 10 \\
\hline & Maximum plastic strain & $2 \mathrm{e}-3$ & $2 \mathrm{e}-3$ & $2 \mathrm{e}-3$ & $2 e-3$ & $2 \mathrm{e}-3$ \\
\hline & $\begin{array}{l}\text { Deactivation criterion } \\
{[\mathrm{mm} / \mathrm{mm}]}\end{array}$ & $\mathrm{N} / \mathrm{A}$ & 0.023 & 0.008 & N/A & 0.0125 \\
\hline \multirow{2}{*}{$\begin{array}{l}\text { CL (upper) } \\
\text { Contacts }\end{array}$} & Contact cohesion & 0.5 & 0.5 & 0.5 & 0.5 & 0.5 \\
\hline & Contact friction angle & $25^{\circ}$ & $25^{\circ}$ & $30^{\circ}$ & $15^{\circ}$ & $20^{\circ}$ \\
\hline \multirow{2}{*}{$\begin{array}{l}\text { CL (lower) } \\
\text { Contacts }\end{array}$} & Contact cohesion & 0.5 & 0.5 & 0.5 & 0.5 & 0.5 \\
\hline & Contact friction angle & $25^{\circ}$ & $30^{\circ}$ & $40^{\circ}$ & $30^{\circ}$ & $30^{\circ}$ \\
\hline \multirow{2}{*}{$\begin{array}{l}\text { Qzite } \\
\text { Contacts }\end{array}$} & Contact cohesion & 0.5 & - & - & 0.5 & 0.5 \\
\hline & Contact friction angle & $25^{\circ}$ & - & - & $30^{\circ}$ & $30^{\circ}$ \\
\hline
\end{tabular}

